\title{
Fracture Toughness Testing and Prediction for Ceramic Materials Using in Large-Flow-Rate Emulsion Pumps
}

\author{
Ran Li ${ }^{1, ~ *, ~ W e n s h u ~ W e i ~}{ }^{1}$, Shoubin $\mathrm{Li}^{1}$, Yinshui Liu ${ }^{2}$, Hao Liu ${ }^{1}$, Huigang Wu ${ }^{1}$, Wei Wang ${ }^{1}$, Jian Ye ${ }^{1}$, \\ Chenjin Tian ${ }^{1}$, Dalong Wang ${ }^{1}$, Mengyu Wu ${ }^{1}$, Jiankai Zhang ${ }^{1}$ \\ ${ }^{1}$ Beijing Tiandi-Marco Electronic-Hydraulic Control System Company Ltd., China Coal Technology and Engineering Group, Beijing, China \\ ${ }^{2}$ Department of Mechanical Engineering, Huazhong University of Science and Technology, Wuhan, China
}

\section{Email address:}

ranli03@163.com (Ran Li)

${ }^{*}$ Corresponding author

\section{To cite this article:}

Ran Li, Wenshu Wei, Shoubin Li, Yinshui Liu, Hao Liu, Huigang Wu, Wei Wang, Jian Ye, Chenjin Tian, Dalong Wang, Mengyu Wu, Jiankai Zhang. Fracture Toughness Testing and Prediction for Ceramic Materials Using in Large-Flow-Rate Emulsion Pumps. International Journal of Mechanical Engineering and Applications. Vol. 7, No. 2, 2019, pp. 46-53. doi: 10.11648/j.ijmea.20190702.12

Received: April 20, 2019; Accepted: May 28, 2019; Published: June 12, 2019

\begin{abstract}
Fracture toughness $\left(\mathrm{K}_{\mathrm{IC}}\right)$ tests have been carried out on single edge precracked beam specimens with dimensions in accordance with ISO15732 requirements for two types of zirconia and one type of alumina, i.e. $\mathrm{ZrO}_{2}-1, \mathrm{ZrO}_{2}-2$ and $\mathrm{Al}_{2} \mathrm{O}_{3}$. Experimental determinations of $\mathrm{K}_{\mathrm{IC}}$ for the two zirconia and one alumina materials are $12.18 \mathrm{MPa} \cdot \mathrm{m}^{1 / 2}, 16.35 \mathrm{MPa} \cdot \mathrm{m}^{1 / 2}$ and 4.99 $\mathrm{MPa} \cdot \mathrm{m}^{1 / 2}$, respectively. The median rank method is used to calculate the probability of fracture, $\mathrm{F}\left(\mathrm{K}_{\mathrm{IC}}\right)$ of the three cermaic materials for representing the experimental results. The SEM analysis on fracture surfaces of $\mathrm{ZrO} 2-1$ materials is carried out, which indicates the fracture in $\mathrm{ZrO}_{2}-1$ material occurred at the interior of the grain associated with interior stress distribution with principal components of $\mathrm{ZrO}_{2}$ and $\mathrm{SiO}_{2}$. Th extended finite element method (XFEM), based on the linear elastic fracture mechanics in conjuciton with a bilinear traction-separation damage law, is used to simulate the progressive crack growth process in the SEPB specimens. The XFEM predicted $\mathrm{K}_{\mathrm{IC}}$ results are compared with the corresponding experimental data. The XFEM approach overpredicts the $\mathrm{K}_{\mathrm{IC}}$ values, from $10.4 \%$ to $25.6 \%$, for the three ceramic materials. The possible reasons, in the aspect of loading conditions and contact assumptions, for the difference between the predicted and tested results are also discussed.
\end{abstract}

Keywords: Fracture Toughness, Single Edge Precracked Beam, Zirconia, Alumina, XFEM

\section{Introduction}

In order to meet the requirements of the hydraulic support used in the longwall face with the large mining height, in terms of high setting force, high working resistance and safety supporting, a high-power emulsion pump system is required, for providing the high-pressure flow with large flow rates [1-2]. With the advantages of excellent wear and corrosion resistance, high hardness and thermal stability, etc., the ceramic plunger is ideal for periodically changing the working chamber volume of the emulsion pump in order to generate the liquid flow.

Potential failures of the ceramic components are often associated with the brittleness behaviour of those ceramic materials. The fracture toughness, $\mathrm{K}_{\mathrm{IC}}$, is an essential fracture mechanics parameter for characterizing the resistance of a material to fracture. Several methods for testing the fracture toughness of ceramic materials are widely used, such as, single edge precracked beam (SEPB) method [2], indentation method [4], surface cracking flexure (SCF) method [5], chevron notched beam method [6], double cantilever beam (DCB) [7], etc. The SEPB method is mostly widely used, which was standardized by ISO 15732-2003.

The extended finite element method (XFEM), was proposed by Belytschko and co-workers in 1999 [8], for alleviating the problems encountered in FE analyses of the modelling of moving discontinuities. The XFEM has been successfully used to solve a number of fracture toughness investigations. Nagamani et al [9] have implemented the XFEM combined with experimental data of microbeam bend tests for determining the fracture toughness of graded 
(Pt,Ni)Al bond coats. Eftekhari et al [10] have proposed an XFEM multiscale approach for investigating the fracture behaviour of carbon nanotube reinforced concrete specimen. Goel et al [11] have applied the XFEM to investigate the fracture toughness of the rolled Zircaloy-2 at different temperatures. Lee and his co-workers [12-13] have used the XFEM to evaluate the fracture toughness of brittle materials by the use of indentation method.

In this paper, the fracture toughness test programme using SEPB specimens according to ISO15732-2003 standard and experimental results were introduced. Finite element (FE) analyses were performed, by the use of the XFEM approach, in order to predict the fracture toughness values for three ceramic materials, subjected to different applied forces. The XFEM predictions were validated by the experimental results. The XFEM results overpredict the $\mathrm{K}_{\mathrm{IC}}$ values, from $10.4 \%$ to $25.6 \%$, compared with the experimental results.

\section{Fracture Toughness Tests}

\subsection{Test Specimens and Test Procedure}

Two types of zirconia, with different chemical components, i.e., $\mathrm{ZrO}_{2}-1$ and $\mathrm{ZrO}_{2}-2$, and alumina, i.e., $\mathrm{Al}_{2} \mathrm{O}_{3}$ were used in this study. The chemical analyses of the three ceramic materials are shown in Table 1. The material properties of the three ceramic materials are shown in Table 2 , which were obtained by additional tests. The tested specimens used are standard SEPB specimens, with dimensions in accordance with ISO15732-2003 requirements [3], as can been seen in Figure 1. The total length, L, the width, w, and the thickness, $d$ of the SEPB specimens are in the values of $40 \mathrm{~mm}, 4 \mathrm{~mm}$ and $3 \mathrm{~mm}$, respectively. Two types of pre-crack were machined using the straight-through saw notch, with initial crack lengths, $1_{1}=0.4 \mathrm{~mm}$ and $l_{2}=1.9 \mathrm{~mm}$ for $\mathrm{ZrO}_{2}-1$ and $\mathrm{ZrO}_{2}-2$, respectively.

Table 1. Compositions of the three ceramic materials (wt\%).

\begin{tabular}{|c|c|c|c|c|c|c|c|c|c|c|}
\hline Material & $\mathrm{CaO}$ & MgO & $\mathbf{K}_{2} \mathrm{O}$ & $\mathrm{Na}_{2} \mathrm{O}$ & $\mathrm{Fe}_{2} \mathrm{O}_{3}$ & $\mathrm{SiO}_{2}$ & $\mathrm{Al}_{2} \mathrm{O}_{3}$ & $\mathrm{TiO}_{2}$ & $\mathrm{ZrO}_{2}$ & $\mathrm{Y}_{2} \mathrm{O}_{3}$ \\
\hline $\mathrm{ZrO} 2-1$ & 0.0074 & 0.0096 & 0.00058 & 0.0011 & 0.0052 & 0.36 & 0.75 & 0.014 & 92.54 & 5.84 \\
\hline $\mathrm{ZrO} 2-2$ & 0.006 & 0.036 & 0.11 & 0.014 & 0.19 & 0.22 & 1.45 & 0.22 & 91.27 & 6.09 \\
\hline $\mathrm{A} 12 \mathrm{O} 3$ & 0.24 & 0.048 & 0.0046 & 0.062 & 0.0012 & 0.55 & 99.09 & - & - & - \\
\hline
\end{tabular}

Table 2. Material properties of the three ceramic materials.

\begin{tabular}{llll}
\hline Material & Elastic modulus, E (GPa) & Poisson's ratio, v & Density, $\boldsymbol{\rho}\left(\mathbf{k g} / \mathbf{m}^{\mathbf{3}}\right)$ \\
\hline $\mathrm{ZrO}_{2}-1$ & 232 & 0.28 & $6.07 \times 103$ \\
$\mathrm{ZrO}_{2}-2$ & 213 & 0.23 & $6.07 \times 103$ \\
$\mathrm{Al}_{2} \mathrm{O}_{3}$ & 423 & 0.23 & $3.89 \times 103$ \\
\hline
\end{tabular}

The test rig, used for testing the SEPB specimens, are AGIC $100 \mathrm{kN}$ digital universal testing machine, as shown in Figure 2(a). The test rig was automated using a computer and the control was achieved using a digital controller. The threepoint bend test fixture was used for each specimen, as can be seen in Figure 2(b). The bend test fixture is designed to allow rolling contact and avoid frictional wedging of the specimen, in order to minimize the frictional effect of the contacts for pin-to-specimen and specimen-to-support. The distance between supporting roller pins in the bend test fixture, $d_{l}$, was $30 \mathrm{~mm}$. Five tests were carried out for each ceramic material, in order to obtain the average $\mathrm{K}_{\mathrm{IC}}$ value. The micro strain gauges were attached to the specimens, in order to interpret the bending stresses and displacement. Figure 2(c) shows the layout of the strain gauge installations on the SEPB specimen.

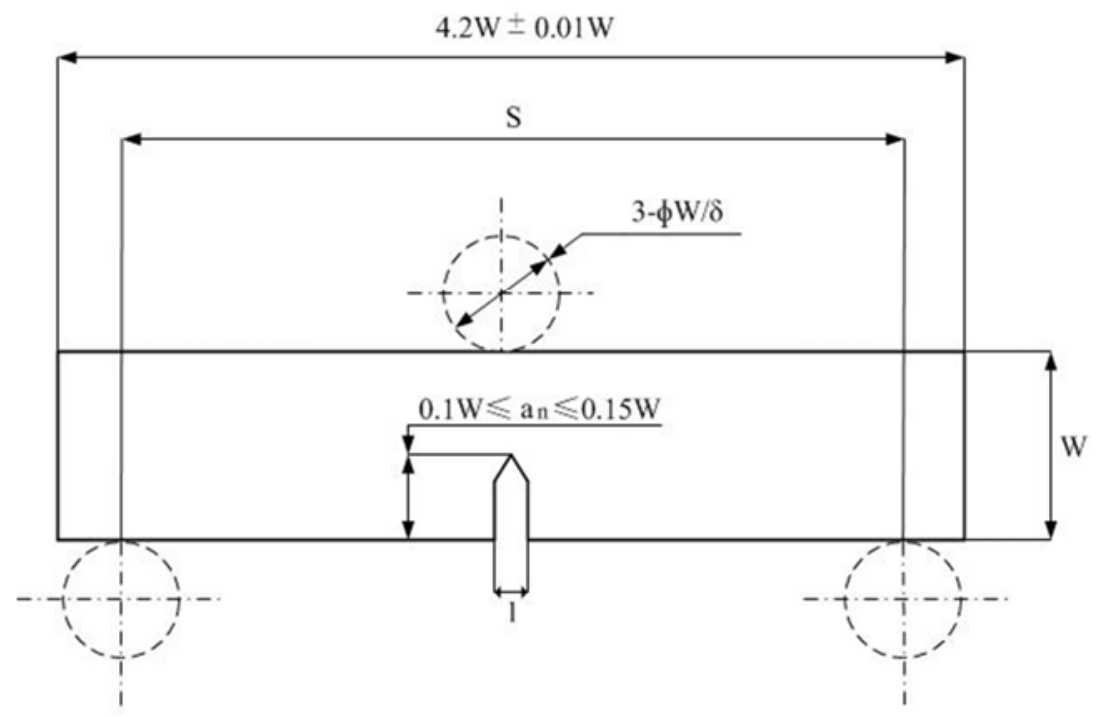

Figure 1. Configuration of the SEPB specimen. 


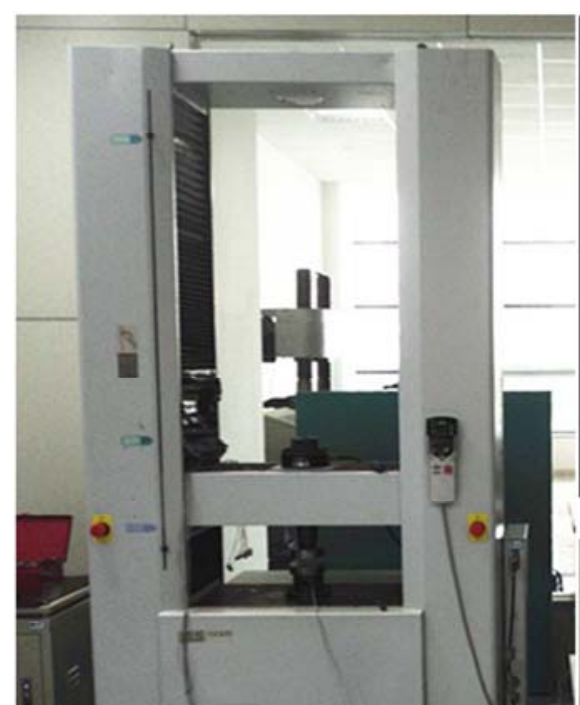

(a)

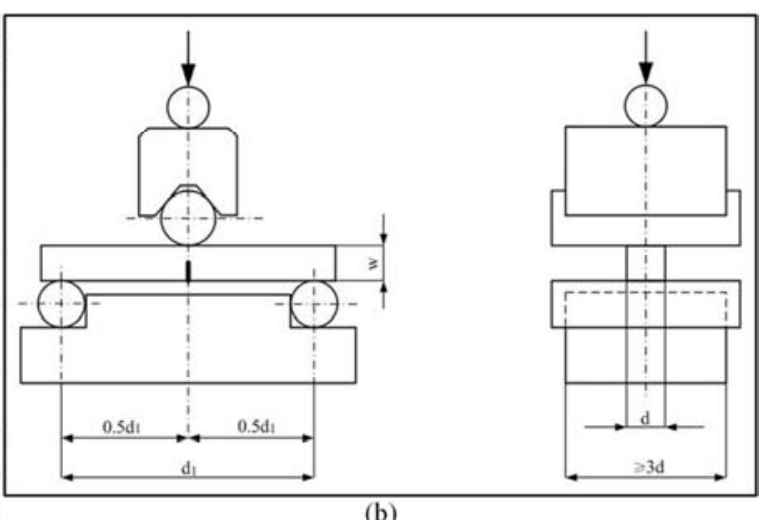

(b)

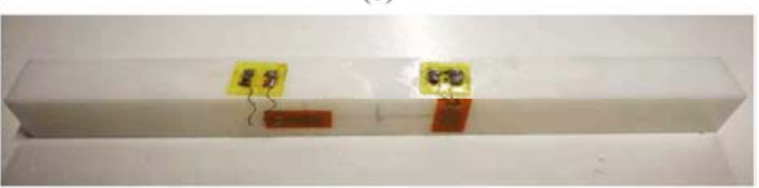

(c)

Figure 2. Apparatus and preparation of SEPB tests: (a) test rig (b) schematic diagrams of test fixture and (c) the layout of strain gauge installations.

\section{2. $K_{I C}$ Calculation}

According to ISO15732-2003 [3], the $\mathrm{K}_{\mathrm{IC}}$ fracture parameter, for SEPB specimens, can be calculated using the equation as follows:

$$
K_{I C}=\frac{P_{\mathrm{f}} \times d_{1}}{d \times w^{3 / 2}}\left[\frac{3}{2}\left(\frac{l}{w}\right)^{1 / 2} \times Y\left(\frac{l}{w}\right)\right]
$$

where, in the case of the 3-point bend specimen (applicable range of formula: $0.35 \leq \frac{l}{w} \leq 0.6$ )

$$
Y\left(\frac{l}{w}\right)=1.964-2.837 \frac{l}{w}+13.711\left(\frac{l}{w}\right)^{2}-23.250\left(\frac{l}{w}\right)^{3}+24.129\left(\frac{l}{w}\right)^{4}
$$

where $P_{f}$ is the maximum applied force before fracture.

\subsection{Experimental Results}

\subsubsection{General Findings}

Figure 3 shows two typical load versus time curves for $\mathrm{ZrO}_{2}-1$ and $\mathrm{Al}_{2} \mathrm{O}_{3}$. As can be seen in Figure 3, the maximum applied load for zirconia is about $397.5 \mathrm{~N}$, which is higher than that for alumina by a factor of $\sim 2.6$. Hence, the $\mathrm{K}_{\mathrm{IC}}$ values for zirconia and alumina can be obtained by the use of Equation 1. Table 3 shows the tested average results of five test specimens for the three materials.

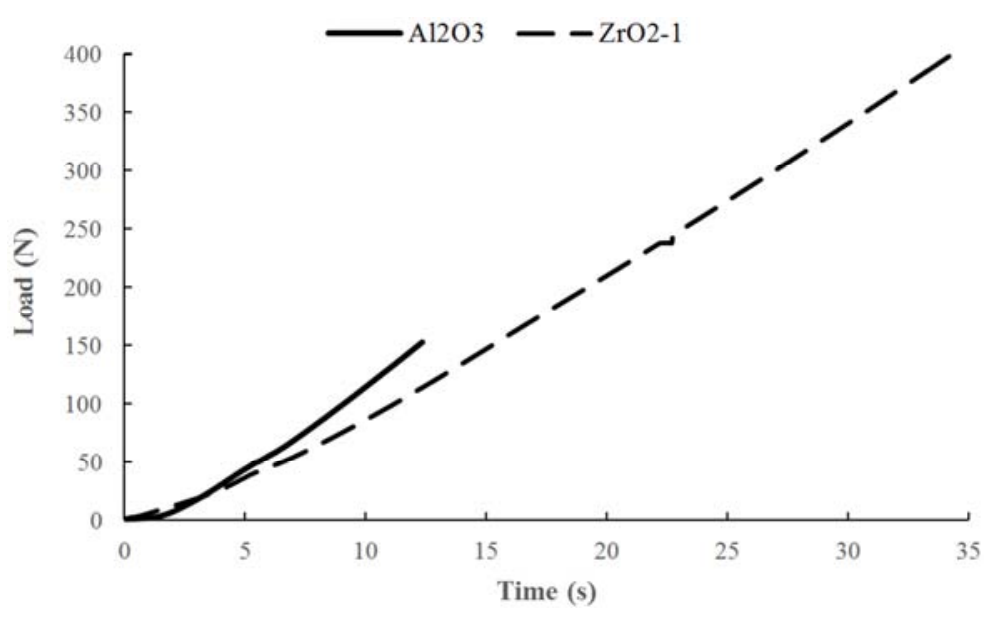

Figure 3. Typical load versus time curves for both zirconia and alumina. 
Table 3. Tested average results of each test specimen for the three ceramic materials.

\begin{tabular}{llll}
\hline Material & Average $\boldsymbol{P}_{\boldsymbol{f}}, \mathbf{( N )}$ & Average maximum bending stress $(\mathbf{M P a})$ & Average $\mathbf{K}_{\mathrm{IC}}\left(\mathbf{M P a} \cdot \mathbf{m}^{\mathbf{1} / \mathbf{2}}\right)$ \\
\hline $\mathrm{ZrO}_{2}-1$ & 359.2 & 336 & 12.18 \\
$\mathrm{ZrO}_{2}-2$ & 154.2 & $\mathrm{~N} / \mathrm{A}$ & 16.35 \\
$\mathrm{Al}_{2} \mathrm{O}_{3}$ & 143.3 & 129 & 4.99 \\
\hline
\end{tabular}

The average values of the tested bending stresses for $\mathrm{ZrO}_{2}-1$ and $\mathrm{Al}_{2} \mathrm{O}_{3}$ are $336 \mathrm{MPa}$ and $129 \mathrm{MPa}$, respectively. The theoretical maximum bending stress for the SEPB specimen can be calculated by Equation 3 .

$$
\sigma_{\max , S E P B}=\frac{3}{2} \times \frac{P_{f} d_{1}}{d w^{2}}
$$

$0.22 \%$ and $4.14 \%$ differences between the tested and theoretical bending stress can be found for $\mathrm{ZrO}_{2}-1$ and $\mathrm{Al}_{2} \mathrm{O}_{3}$, respectively. The theoretical maximum bending stresses are in close agreement with the test data for $\mathrm{ZrO}_{2}-1$ and $\mathrm{Al}_{2} \mathrm{O}_{3}$.

\subsubsection{Fracture Toughness Results}

The Weibull distribution function has been widely used in characterizing scatter in fracture toughness results of brittle materials due to its versatility and relative simplicity [14]. In the case of fracture toughness, the two parameter Weibull distribution function can be written in the form of

$$
F\left(K_{I C}\right)=1-\exp \left(-\left(\frac{K_{I C}}{K_{0}}\right)^{m}\right)
$$

where $\mathrm{F}\left(\mathrm{K}_{\mathrm{IC}}\right)$ is the probability of fracture, $\mathrm{K}_{0}$ is the normalization factor which is equal to the value of $\mathrm{K}_{\mathrm{IC}}$ which stands for the failure probability of $0.632, \mathrm{~m}$ is an exponent for quantifying the scatter of $\mathrm{K}_{\mathrm{IC}}$.

The probability of fracture, $\mathrm{F}\left(\mathrm{K}_{\mathrm{IC}}\right)$ can be calculated using the median rank method. The plot of the probability of fracture against the fracture toughness results of the tested materials is shown in Figure 4. The two parameters for Weibull distribution function, $\mathrm{K}_{0}$ and $\mathrm{m}$, can be obtained by rearranging and taking twice the logarithm of Equation 4, which are given in Table 4.

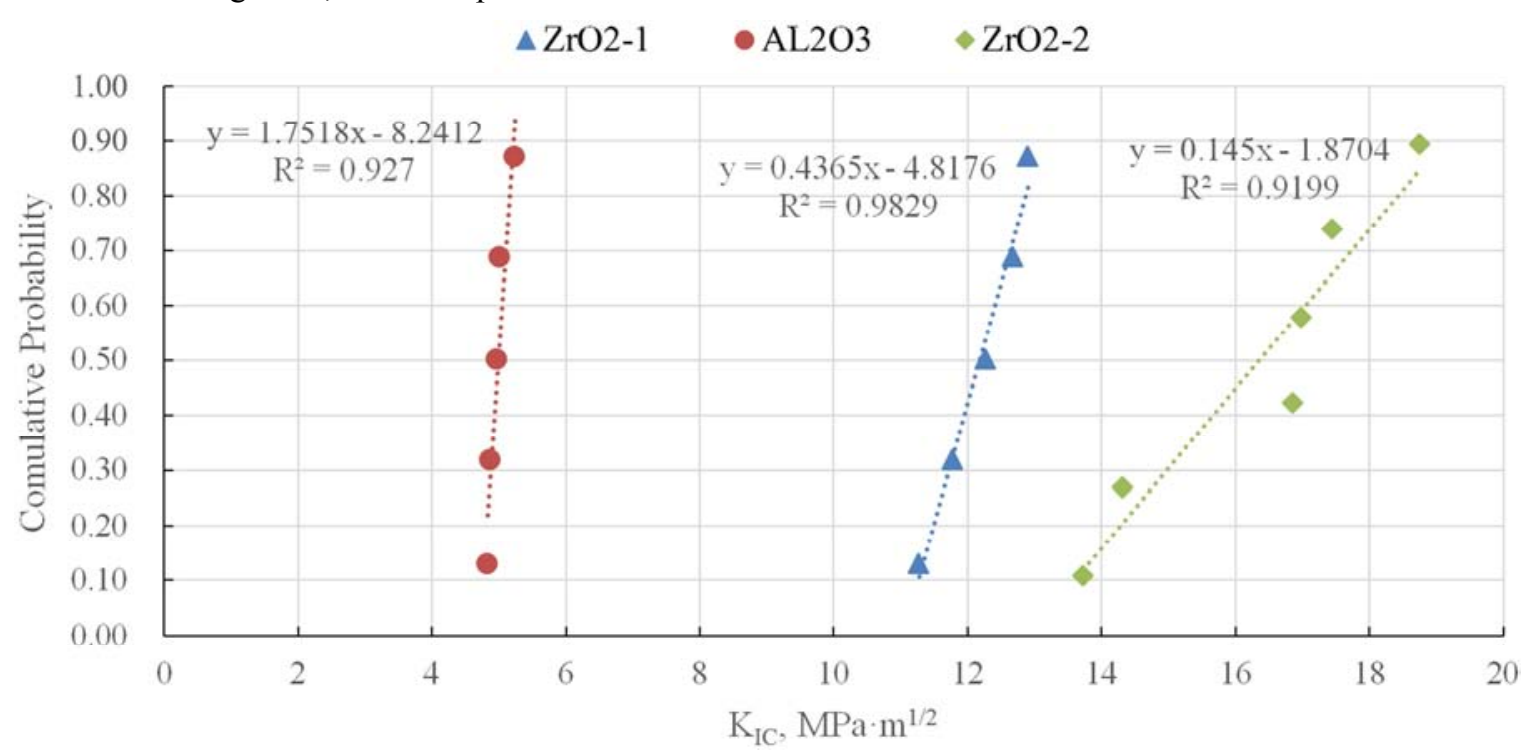

Figure 4. Plot of the probability of fracture against the fracture toughness results.

Table 4. Parameters of Weibull distribution for the three ceramic materials.

\begin{tabular}{lll}
\hline Material & $\mathbf{K}_{\mathbf{0}}$ & $\mathbf{m}$ \\
\hline $\mathrm{ZrO}_{2}-1$ & 12.49 & 18.73 \\
$\mathrm{ZrO}_{2}-2$ & 8.42 & 17.25 \\
$\mathrm{Al}_{2} \mathrm{O}_{3}$ & 5.07 & 30.27 \\
\hline
\end{tabular}

\subsubsection{SEM Observations of Fracture Morphology}

Figure 5 show the SEM images of typical fracture surface of $\mathrm{ZrO}_{2}-1$ material. The fine grains $(<5 \mu \mathrm{m})$ and coarse grains $(>20 \mu \mathrm{m})$ can be found in Figure 5. It can be seen that a mixture of intergranular and transgranular cracking dominates the fracture mode in $\mathrm{ZrO}_{2}-1$ material. The grain boundary fracture energy is much lower than the cleavage energy, due to the presence of debris, pores and dislocations. Hence, the nucleation of microcracks can be formed at grain boundaries. The fracture in $\mathrm{ZrO}_{2}-1$ material also occurred at the interior of the grain associated with interior stress distribution with principal components of $\mathrm{ZrO}_{2}$ and $\mathrm{SiO}_{2}$. 


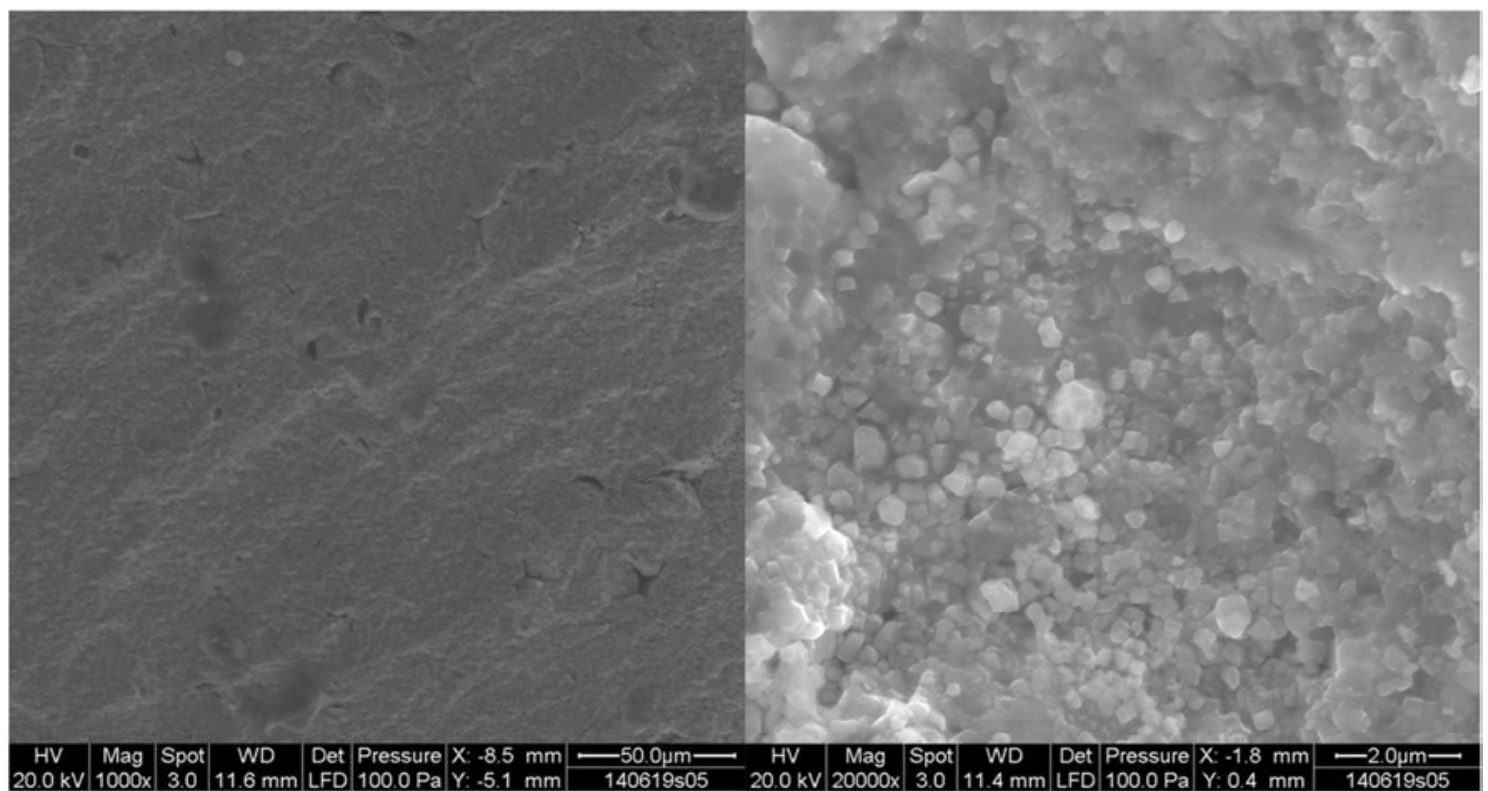

(a)

(b)

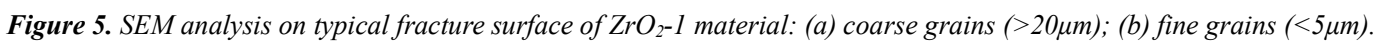

\section{The XFEM Approach}

\subsection{Displacement Approximation}

The XFEM approach is based on the enrichment of the finite element analysis with additional degrees of freedom, in order to represent the discontinuities in the elements across a localized crack. The theoretical basis of the XFEM is related to the concept of the partition of unity. A set of the standard finite element shape functions can be used as the partitions of unity, with the enriched part of the displacement field. Hence, the XFEM displacement approximation can be expressed as [15]

$$
u^{h}(x)=\sum_{i \in I} u_{i} N_{I}+\sum_{i \in J} a_{i} \tilde{N}_{J} H(x)+\sum_{i \in K} \tilde{N}_{K}\left(\sum_{\alpha=1}^{4} F_{\alpha}(x) b_{i}^{\alpha}\right)
$$

where $I$ is the set of all nodes in the mesh; $J$ is the set of nodes in the affected domains which are embedded by the crack; $\mathrm{K}$ is the set of nodes in the affected domains at both ends of the crack tip. $N_{I}, \tilde{N}_{J}$ and $\tilde{N}_{K}$ are the nodal shape function. $u_{i}$ are the displacement nodal degrees of freedom. $a_{i}$ and $b_{i}^{\alpha}$ are the enriched degrees of freedom for the nodal displacement. The discontinuity in the enriched part of the displacement field can be represented by the Heaviside jump function as:

$$
H(x)=\left\{\begin{array}{c}
1, \text { if }\left(x-x^{*}\right) \cdot n \geq 0 \\
-1, \text { otherwise }
\end{array}\right.
$$

where $x^{*}$ is the closest point of the crack to the point $x$ and $n$ is the outward normal vector at $x^{*}$.

$F_{\alpha}(x)$ is the crack-tip enrichment function, based on the linear elastic fracture mechanics, for isotropic material, which can be adopted as [16]

$$
F_{\alpha}(r, \theta)=\left\{\sqrt{r} \sin \frac{\theta}{2}, \sqrt{r} \cos \frac{\theta}{2}, \sqrt{r} \sin \theta \sin \frac{\theta}{2}, \sqrt{r} \sin \theta \cos \frac{\theta}{2}\right\}
$$

where $(r, \theta)$ are the local polar coordinates at the crack tip.

\subsection{Damage Law}

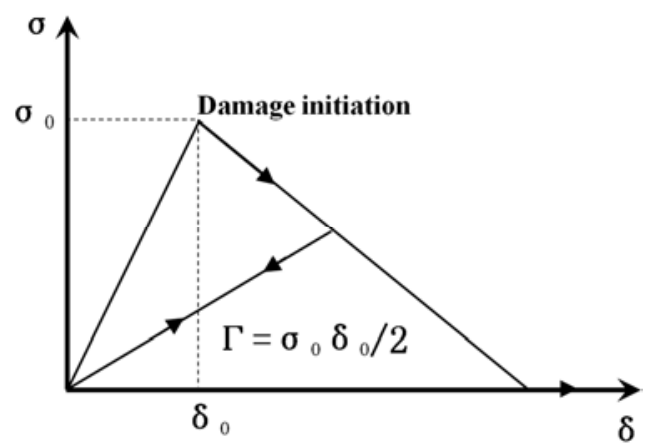

Figure 6. Schematically representation of a bilinear traction-separation law.

The concept of the traction-separation $(\sigma-\delta)$ behaviour proposed by Barenblatt [17], was used for governing the damage initiation and damage evolution process. Figure 6 schematically shows a bilinear traction-separation law for describing the damage initiation and propagation. The damage initiation follows the ascending linear branch of the bilinear traction-separation law when the damage initiation 
criterion is satisfied. The damage initiation criterion is based on the maximum principle stress, $\sigma_{n}$, as shown in Equation 8. Damage in the form of microcrack and small-scale defect initiates when the maximum principle stress reaches a critical value (i.e. $f=1$ ).

$$
f=\frac{\left\langle\sigma_{n}\right\rangle}{\sigma_{\max }^{0}}
$$

Damage evolution occurs according to the descending linear branch of bilinear traction-separation law, associated with the material softening behaviour and stiffness degradation. Fracture energy $\mathrm{G}_{\mathrm{IC}}$ was used for describing the damage evolution criterion [18]. Equation 9 gives the relationship between the fracture energy, $\mathrm{G}_{\mathrm{IC}}$ and fracture toughness, $\mathrm{K}_{\mathrm{IC}}$. A damage parameter, $D$, measures the degree of the damage, with $D=0$ indicating the original material and $D=1$ referring to total failure. Damage propagates when the damage parameter varies from 0 and 1 .

$$
G_{I C}=\frac{K_{I C}^{2}}{E}
$$

\section{XFEM Predictions}

Figure 7. A 2D FE model for SEPB fracture toughness testing.

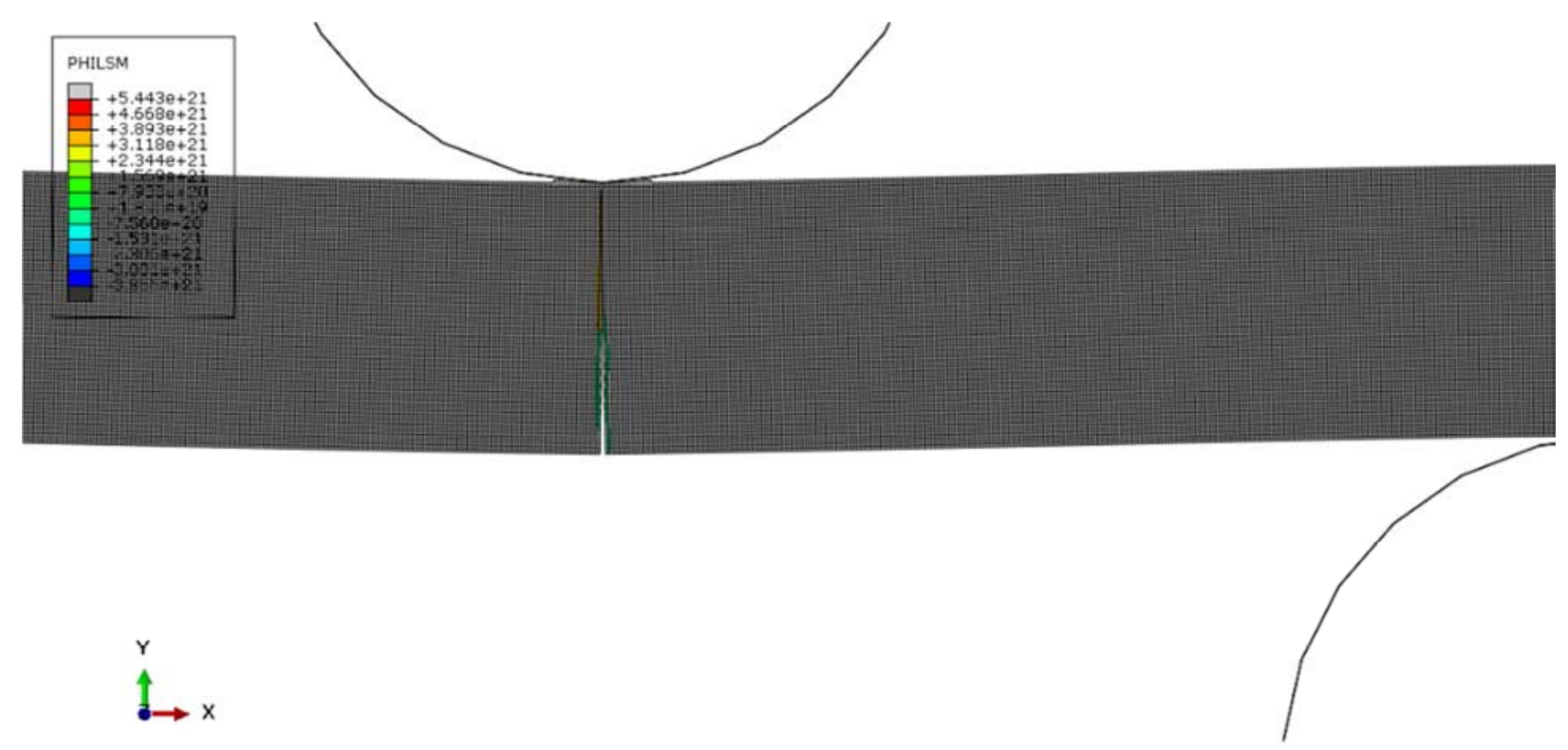

Figure 8. A typical XFEM result of SEPB test.

A two-dimensional (2D) FE model was created for single edge precracked beam (SEPB) specimen, using the commercial code, ABAQUS [19], as shown in Figure 7. The initial crack, $1_{1}=0.4 \mathrm{~mm}$ or $l_{2}=1.9 \mathrm{~mm}$, was modelled to the specimen by a "seam", which is an in-built function within ABAQUS [19]. 4-noded bilinear plane strain (CPS4E) elements were used for the mesh of the SEPB specimen, with the global mesh size of 0.05 , this allows large strain and large 
deformation to be modelled. The loading roller pin and supports were represented by analytical rigid bodies, in order to eliminate the possibility of elastic-plastic deformation occurring in these components. The small sliding assumption was used for the contacts for both pin-to-specimen and specimen-to-support. The coefficient of friction was taken to be a constant value, i.e. 0.01 , for all of the contacts. The material properties of the three ceramic materials, used for the FE models, are given in Table 2. The ultimate bending strength was used for the critical value of the maximum principle stress, which was suggested by many researchers, e.g. [20]. The values of fracture energy $\mathrm{G}_{\mathrm{IC}}$ were calculated using Equation 1, which are $0.059 \times 10^{-3} \mathrm{MPa} \cdot \mathrm{m}, 0.639 \times 10^{-}$ ${ }^{3} \mathrm{MPa} \cdot \mathrm{m}$ and $1.255 \times 10^{-3} \mathrm{MPa} \cdot \mathrm{m}$ for $\mathrm{ZrO}_{2}-1, \mathrm{ZrO}_{2}-2$ and $\mathrm{Al}_{2} \mathrm{O}_{3}$, respectively. The loading was applied to the reference point of the punch in terms of velocity, $\mathrm{V}_{\mathrm{i}}$. The FE applied load $P_{f}^{F E}$ was calculated by the reaction loads of two supports in the loading direction. A typical XFEM result for $\mathrm{ZrO}_{2}-1$ is shown in Figure 8. The output variable PHILSM is used for visualizing crack in the SEPB specimens. The geometric parameters are given in Section 2.1, the XFEM predicted $\mathrm{K}_{\mathrm{IC}}$ values can be obtained by the use of Equation 1 , which were $13.45 \mathrm{MPa} \cdot \mathrm{m}^{1 / 2}, 20.40 \mathrm{MPa} \cdot \mathrm{m}^{1 / 2}$ and 6.27 $\mathrm{MPa} \cdot \mathrm{m}^{1 / 2}$ for $\mathrm{ZrO}_{2}-1, \mathrm{ZrO}_{2}-2$ and $\mathrm{Al}_{2} \mathrm{O}_{3}$, respectively.

\section{Discussions}

\subsection{Influence of Chemical Composition and Initial Crack Size}

The tested $\mathrm{K}_{\mathrm{IC}}$ values of $\mathrm{ZrO}_{2}-2$ are about $34 \%$ higher than those of $\mathrm{ZrO}_{2}-1$. The differences in the chemical compositions between $\mathrm{ZrO}_{2}-1$ and $\mathrm{ZrO}_{2}-2$ are the weight percent of $\mathrm{Fe}_{2} \mathrm{O}_{3}$ and $\mathrm{Al}_{2} \mathrm{O}_{3}$, as shown in Table 2. $\mathrm{Fe}_{2} \mathrm{O}_{3}$ is the colourant additions which only affects the colour of zirconia and has little effect on the mechanical properties [21]. The weight percent of $\mathrm{Al}_{2} \mathrm{O}_{3}$ is $0.75 \mathrm{wt} \%$ for $\mathrm{ZrO}_{2}-1$, while this value increases to $1.45 \mathrm{wt} \%$ for $\mathrm{ZrO}_{2}-2$. Schierano et al [22] have found that the combination of alumina and zirconia allows the improvement of the mechanical performance of zirconia, due to the minoring the ageing effect of zirconia. Nojima et al [23] have investigated that the $\mathrm{K}_{\mathrm{IC}}$ value increases with an increase in the length of initial crack for both a glass and an alumina ceramic. It seems to be reasonable explanations for the differences in the $\mathrm{K}_{\mathrm{IC}}$ values between $\mathrm{ZrO}_{2}-1$ and $\mathrm{ZrO}_{2}-2$.

\subsection{Comparison Between SEPB Tests and Other Methods}

The experimental results obtained from SEPB tests were companied with those obtained from other methods [2, 22-24], as shown in Table 5 . The $\mathrm{K}_{\mathrm{IC}}$ result of alumina obtained from SEPB method was $34.1 \%$ and $113 \%$ larger than those obtained from indentation method [4] and chevron notched beam [26]. The overprediction for the SEPB method may be related to the blunting effect of crack-tip. The straight-through saw notch was used for the presence of pre-crack. However, the notch was not a sharp crack, which produces the blunting zone in the vicinity of the crack tip. The comparison between the $\mathrm{K}_{\mathrm{IC}}$ for a sharp crack and $\mathrm{K}_{\mathrm{IC}}$, blunt can be found in Reference [27] for ceramic materials, which gives in Equation 10

$$
\frac{K_{I C, \text { blunt }}}{K_{I C}}=\left(1+\frac{\rho_{0}}{2 r_{0}}\right)^{1 / 2}
$$

Where $\rho_{0}$ is the root radius of the blunt crack and $r_{0}$ is the microcrack size near the crack tip. Equation 10 indicates the fracture toughness for the blunting crack is larger than that for a sharp crack. Similar results were also found by Simpson [28]. He investigated the blunting effect of crack-tip for $\mathrm{Al}_{2} \mathrm{O}_{3}$ using SEPB and DCB specimens. He found that the ratio of $\mathrm{K}_{\mathrm{IC}}$ value obtained using $\mathrm{SEPB}$ specimen with $0.5 \mathrm{~mm}$ notch width to that obtained from DCB method is about 1.21.

Table 5. Comparison between SEPB method and the other methods for $K_{I C}$ $\left(\mathrm{MPa} \cdot \mathrm{m}^{1 / 2}\right)$.

\begin{tabular}{lll}
\hline Material & Indentation method & Chevron notched beam \\
\hline $\mathrm{ZrO}_{2}$ & $9.8[24]$ & $7.9[25]$ \\
$\mathrm{Al}_{2} \mathrm{O}_{3}$ & $3.72[4]$ & $2.34[26]$ \\
\hline
\end{tabular}

\subsection{Reasons for XFEM Overprediction}

The experimental loads applied to the specimens were time-dependent. The maximum applied loads, $P_{f}$, were used for calculating the values fracture toughness by the use of Equation 1. For simplicity, the displacement rates were used as loading condition in this study, which would be believed to contribute to the XFEM overpredictions. On the other hand, the punch-specimen contact was assumed to be nearly frictionless, in order to eliminate the influence of friction between punch-specimen contact on the numerical results, which would result in nonphysical contact behaviour. Hence, the realistic contact behaviour should be involved for the XFEM analyses in the future.

\section{Concluding Remarks}

Fracture toughness tests using SEPB specimens according to ISO15732-2003 standard have been carried out for three ceramic materials. The test results were characterized in terms of the two parameter Weibull distribution function. The SEM observations of $\mathrm{ZrO} 2-1$ material indicate that the fracture mode was dominated by a mixture of intergranular and transgranular cracking. The XFEM approach overpredicts the fracture toughness values, which are $10.4 \%, 24.8 \%$ and $25.6 \%$, higher than those obtained from the tests for $\mathrm{ZrO}_{2}-1, \mathrm{ZrO}_{2}-2$ and $\mathrm{Al}_{2} \mathrm{O}_{3}$, respectively. The influences of chemical composition and initial crack size on the SEPB tests were discussed for $\mathrm{ZrO}_{2}-1$ and $\mathrm{ZrO}_{2}$-2. In comparing SEPB method with the other test methods, the blunting effect of crack-tip was considered as a reason that the SEPB test results are relatively large. The possible reasons for the overprediction of $\mathrm{K}_{\mathrm{IC}}$ values obtained from XFEM analyses were discussed in the aspect of loading conditions and contact assumptions. 


\section{Acknowledgements}

This research was supported by The National Key Research and Development Program of China (2017YFC0804300, 2017YFC0804304), NDRC project (NDRC Investment (2015) No. 1780) and CCTEG project (2018-TD-ZD015, 2018MS027) funding.

\section{References}

[1] Wang Guofa, Pang Yihui, Xu Yajun, et al. Longwall mining technology and equipment system integration [M]. Beijing: Coal Industry Press, 2016.

[2] Li Ran, Wang Wei, Su Zhe. Numerical study on thermohydrodynamic performance of journal bearing in highpressure and large-flow-rate emulsion pump [J]. Journal of China Coal Society, 2014, 39 (S2): 576-582.

[3] ISO15732-2003 [S]. Fine ceramics (advanced ceramics, advanced technical ceramics) - Test method for fracture toughness of monolithic ceramics at room temperature by single edge precracked beam (SEPB) method, International Organization Standardization, 2003.

[4] Warren P D. Determining the fracture toughness of brittle materials by hertzian indentation. Journal of the European Ceramic Society 1995, 15 (3): 201-207.

[5] Quinn G D, Swab J J, Hill M D. Fracture toughness by the surface crack in flexure (SCF) method: new test results. In: Proceedings of the 21st Annual Conference on Composites, Advanced Ceramics, Materials, and Structures-B: Ceramic Engineering and Science Proceedings. Cocoa Beach: AcerS, 1994, 18 (4).

[6] Yan J, Clifton K B, Jr M J, et al. Fracture toughness of manatee rib and bovine femur using a chevron-notched beam test. Journal of Biomechanics 2006, 39 (6): 1066-1074.

[7] Wang B L and Wang K F. Effect of surface residual stress on the fracture of double cantilever beam fracture toughness specimen. Journal of Applied Physics 2013, 113 (15): 83.

[8] Moes N, Dolbow, J and Belytschko T. A finite element method for crack growth without remeshing. International Journal for Numerical Methods in Engineering, 1999, 46 (1): 131-150.

[9] Nagamani J B, Vikram J and Sanjay K B. A new method for fracture toughness determination of graded (pt,ni)al bond coats by microbeam bend tests. Philosophical Magazine, 2012, 92 (25-27): 3326-3345.

[10] Eftekhari M, Ardakani S H and Mohammadi S. An XFEM multiscale approach for fracture analysis of carbon nanotube reinforced concrete. Theoretical \& Applied Fracture Mechanics, 2014, 72 (1): 64-75.

[11] Goel S, Kumar N, Fuloria D, et al. Evaluating fracture toughness of rolled zircaloy-2 at different temperatures using XFEM. Journal of Materials Engineering \& Performance, 2016, 25 (9): 1-13.

[12] Rickhey F, Jin H L, Lee H. XFEM investigation on knoop indentation cracking: fracture toughness and aspect-ratio of radial-median cracks. Materials \& Design 2016, 107: 393-405.
[13] Marimuthu K P, Rickhey F, Jin H L, et al. Spherical indentation for brittle fracture toughness evaluation by considering kinked-cone-crack. Journal of the European Ceramic Society 2017, 37 (1): 381-391.

[14] Wallin K, Saario T and Törrönen K. Theoretical Scatter in Brittle Fracture Toughness Results Described by the Weibull Distribution. Application of Fracture Mechanics to Materials and Structures. Springer Netherlands, 1984: 511-518.

[15] Moes N, Dolbow J and Belytschko T. A finite element method for crack growth without remeshing. International Journal for Numerical Methods in Engineering 1999, 46 (1): 131-150.

[16] Xu S L and Reinhardt H W. A Simplified method for determining double- $\mathrm{K}$ fracture parameters for three point bending tests $[\mathrm{J}]$. International Journal of Fracture 2000, 104 (2): $181-200$.

[17] Barenblatt G I. The formation of equilibrium cracks during brittle fracture. General ideas and hypotheses. Axiallysymmetric cracks. J. Appl. Math. Mech, 1959, 23 (3): 622-636.

[18] Oliveira F. Crack modelling with the extended finite element method. Lisboa: Instituto Superior Técnico, 2013

[19] ABAQUS, Inc. ABAQUS 6.14 standard user manual. Providence, RI: ABAQUS, Inc., 2014.

[20] Mohammadi T, Wan B and Harries K. Intermediate Crack Debonding Model of FRP-Strengthened Concrete Beams Using XFEM. Simulia Community Conference 2013.

[21] Jiang L, Wang C Y, Zheng S N, et al. Effect of $\mathrm{Fe}_{2} \mathrm{O}_{3}$ on optical properties of zirconia dental ceramic. Chinese Journal of Dental Research, 2015, 18 (1): 35-40.

[22] Schierano G, Mussano F, Faga MG, et al. An alumina toughened zirconia composite for dental implant application: in vivo animal results. BioMed Research International, 2015, 5: 157360 .

[23] Nojima T, Tsuyoshi H. Effect of initial crack length and specimen geometry on fracture toughness of rate sensitive ceramics. Journal of the Society of Materials Science Japan, 1995, 44 (499): 445-450.

[24] Harada K, Shinya A, Yokoyama D, et al. Effect of loading conditions on the fracture toughness of zirconia. Journal of Prosthodontic Research, 2013, 57 (2): 82-87.

[25] Trunec $M$ and Chlup Z. Higher fracture toughness of tetragonal zirconia ceramics through nanocrystalline structure. Scripta Materialia, 2009, 61 (1): 56-59.

[26] Mueller M G, Pejchal V, Agar G, et al. Fracture toughness testing of nanocrystalline alumina and fused quartz using chevronnotched microbeams. Acta Materialia, 2015, 86: 385-395.

[27] Deng Z Y, She J, Inagaki Y, et al. Reinforcement by crack-tip blunting in porous ceramics. Journal of the European Ceramic Society, 2004, 24 (7): 2055-2059.

[28] Simpson L A. Use of the notched-beam test for evaluation of fracture energies of ceramics. Journal of the American Ceramic Society, 1974, 57: 151-154. 